\title{
HIV prevention cascade theory and its relation to social dimensions of health: a case for Nigeria
}

This article was published in the following Dove Press journal:

HIVIAIDS - Research and Palliative Care

\author{
Ngozi N Joe-lkechebelu ${ }^{1,2}$ \\ Emmanuel C Azuike ${ }^{1,2}$ \\ Basil E Nwankwo ${ }^{1,3}$ \\ Ifeanyichukwu $\cup$ Ezebialu ${ }^{1,4}$ \\ Williams $O$ Ngene ${ }^{1,5}$ \\ George U Eleje ${ }^{6}$
}

\begin{abstract}
'Health Promotion and Practice Research Unit, Chukwuemeka Odumegwu Ojukwu University Teaching Hospital, Awka,

Nigeria; ${ }^{2}$ Department of Community Medicine, Chukwuemeka Odumegwu Ojukwu University Teaching Hospital, Awka, Nigeria; ${ }^{3}$ Office of the Chief Medical Director, Chukwuemeka Odumegwu Ojukwu University, Teaching Hospital, Awka, Nigeria; ${ }^{4}$ Department of Obstetrics and Gynecology,

Chukwuemeka Odumegwu Ojukwu University Teaching Hospital, Awka, Nigeria; ${ }^{5}$ Department of Physiotherapy, Chukwuemeka Odumegwu Ojukwu University Teaching Hospital, Awka, Nigeria; ${ }^{6}$ Effective Care Research Unit, Department of Obstetrics and Gynecology, Nnamdi Azikiwe University, Nnewi Campus, Awka, Nigeria
\end{abstract}

Background: Nigeria has the second largest HIV epidemic in the world and one of the highest rates of new infection in sub-Saharan Africa. Within the last three decades, majority of HIV programs in Nigeria were treatment strategies with few prevention approaches. The persistence of HIV prevalence despite the treatment blueprint has led to a concerted call to HIV Prevention Cascade (HPC) theory which ensures continuous sophisticated interrelationship that stretches beyond the biomedical interventions of treatment. To our knowledge, there is no previous review on HPC theory in Nigerian context.

Objectives: The aim of this review was to explore and outline the HIV/AIDS prevention cascade theory in relation to the achievement of the global 90-90-90 target set by the United Nations Programme on HIV and AIDS and suggest possible avenues to maximize on strengths and weaknesses of HPC in Nigeria.

Methods: In this mini-review, the authors utilized standardized search measures in the review of published articles in credible domains across the HPC in PubMed, Research gate, Google Scholar, Mendeley Reference Manager and Cochrane Library from January 1980 to December 2018. Referenced sections of the articles identified were used to handsearch additional references not retrieved by the initial search engines. The authors performed an evaluation of selected studies on three cascade theories: epidemiological, behavioral and social science with an integration of the supply, demand and adherence sides.

Results: We included nine review articles reporting three different cascade theories. Only one included study applied the cascade theories exclusively in Nigerian context. We could only conduct narrative synthesis.

Conclusion: There is scarceness of currently published evidence on HPC in Nigerian context. HPC allows for a paradigm shift and sequential process of events to eliminate the epidemic of HIV using HIV prevention perspectives in Nigerian settings. Since data are sparse, more research is needed on HPC theory.

Keywords: HIV, epidemic, HPC, prevention, cascade theory, social dimensions, Nigeria

\section{Background}

Nigeria has had the second largest HIV epidemic in the world and has one of the highest rates of new infection in sub-Saharan Africa. ${ }^{1}$ United Nations Programme on HIV and AIDS (UNAIDS) has estimated that approximately two-thirds of new HIV infections in West and Central Africa in 2017 occurred in Nigeria. ${ }^{1}$ Although the current HIV prevalence is $1.4 \%$ among adults aged 15-49 years, unprotected heterosexual sex accounts for $80 \%$ of new HIV infections in Nigeria, with the majority of remaining HIV infections occurring in key affected populations such as sex workers. ${ }^{2}$ In view of this, within the last three decades, majority of HIV funding
Correspondence: George U Eleje

Effective Care Research Unit, Department of Obstetrics and

Gynaecology, Nnamdi Azikiwe University,

Nnewi Campus, P.M.B., Nnewi, Anambra

State 5025, Nigeria

Tel +234806 8II 7444

Email georgel21@yahoo.com 
programs in Nigeria were directed to treatment strategies as opposed to prevention approaches. In 2014, the Joint UNAIDS and partners launched the 90-90-90 targets; the aim was to diagnose $90 \%$ of all HIV-positive persons, provide antiretroviral therapy (ART) for $90 \%$ of those diagnosed, and achieve viral suppression for $90 \%$ of those treated by $2020{ }^{3}$ However, the continuous increase of HIV prevalence, despite the treatment blueprint, has led to a concerted call for HIV prevention cascade (HPC) theory which ensures continuous intricate interrelationship that stretches beyond the biomedical interventions of treatment. ${ }^{4}$ All these are efforts aimed at achieving UNAIDS 90-90-90 targets.

Widening HIV/AIDS action is backed by a sociological theory, within a reality, which believes in the interlinking of human choices and activities and broader environmental influences. The theory behind HPC is a combination of multi-theories and research paradigms. Epidemiological and behavioral theories propel the treatment cascade while the social-ecological theory with the critical gendered theory of social science buttresses the structural angle in HIV. ${ }^{1}$ HPC is a complementary approach that involves behavioral, biomedical and structural prevention strategies that function at the micro (individual), meso (community) and macro (societal) levels for the contextualized need of an at-risk population. Thus, UNAIDS defines the HPC as a rights-based, evidence-informed and community-owned program that uses a mix of biomedical, behavioral and structural interventions, prioritized to meet the current HIV prevention needs of particular individuals and communities. ${ }^{5} \mathrm{~A}$ number of researchers have reported that combining interventions of biomedical, behavioral and structural approaches will reduce the number of new HIV infections, reduce the vulnerability to HIV and increase the uptake of new prevention approaches. ${ }^{6-8}$ Therefore, a key to HPC acceptance is the acceptability of the intricate interconnectedness of the theoretical linkages.

The three components of an HPC strategy critical to the achievement of high coverage are as follows: demandside interventions that improve risk perception, awareness and acceptability of prevention approaches; supply-side interventions that make prevention products and procedures more accessible and available; and adherence interventions that back current adoption of prevention behaviors, including those with or without prevention products. ${ }^{6}$ Hence, the adaptation of the HPC model reveals the series of activities an individual goes through to access uptake of health services. ${ }^{8-10}$ To our knowledge, there is no previous review on HPC theory in a Nigerian context.

The purpose of this mini-review is to explore and outline the HIV/AIDS prevention cascade theory in relation to the achievement of the global 90-90-90 target set by UNAIDS and suggest possible ways to maximize on strengths and weaknesses of HPC in Nigeria.

\section{Methods}

\section{Searches}

The search of databases was performed in January 2019 by the lead author NNJ. Searches were limited to English language articles. The reference lists of included studies, gray literature, policy documents and relevant websites were also searched.

\section{Information sources}

We searched papers PubMed, Research gate, Google Scholar, Mendeley Reference Manager, Cochrane Library and Cumulative Index to Nursing and Allied Health Literature from January 1980 to December 2018). Referenced sections of the articles identified were used to find additional references not retrieved by the initial search engines. Bibliographies of the original articles retrieved were hand-searched. The following search terms (text words and medical subject headings) were used: social dimensions of health* OR HIV interventions OR prevention effectiveness evaluation AND HIV prevention cascade OR HIV/AIDS prevention cascade OR cascade theories OR HIV cascade theories OR epidemiological OR behavioral OR the social science with an integration of the supply side OR demand side OR the adherence side. The search terms were reviewed and tested with an information specialist.

\section{Inclusion criteria}

We included review articles using standardized measures for domains across the HPC. All titles and abstracts were screened by NNJ and GUE, and the decision to include or exclude was recorded. If multiple papers were published, the multiple reports were treated as a single study. Studies were managed by using reference management software.

\section{Exclusion criteria}

We excluded measures not related to HIV/AIDS health research and measures which focus on singular aspects of HIV (eg, treatment or palliation). We also excluded reviews containing interventions implemented strictly in 
high-income countries. We chose to focus on an area with the highest HIV burden which is in the West African subregion (Nigeria).

\section{Data charting and synthesis}

Data were extracted from papers on three main categories: demand-side context (targets for prevention programs, interventions, platforms for delivery at scale, and policies); supply-side measure, which included the measures (targets for prevention programs, interventions, platforms for delivery at scale, and policies); and adherence side reported as (targets for prevention programs, interventions, platforms for delivery at scale and policies).

Data were extracted and recorded by NNJ only. We undertook a narrative synthesis of the results in line with our research objectives.

\section{Results}

The search identified 2066 articles (Figure 1). We removed 899 duplicates, leaving 1167 for screening. A subsequent sum of 1119 articles were excluded for various reasons (the most common being a nonreview article), leaving 48 articles for full-text inspection. Thirty-nine articles were further excluded, leaving a total of nine journal review articles reporting on three different domains: demand-side context, supply-side measure and adherence-side measures for final inclusion (Figure 1). All primary individual studies were excluded.

Six studies (Coates et al, Amaugo et al, Kirby et al, Krishnaratne et al, Paul-Ebhohimhen et al and Fonner et al) discussed the demand-side interventions for HPC. ${ }^{10-15}$ This is shown in Table 1. These studies emphasized classic behavioral interventions such as information and education campaigns delivered in schools, health settings, communities and through the media. The two studies (Coates et al and Krishnaratne et al) also illustrated that the demandside interventions involve peer and social network-driven interventions. ${ }^{10,13}$ The delivery platforms for demand-side interventions are the media and the school education system.

Two studies (Blankenship et al and Charania et al) discussed the supply-side interventions and recommended that prevention products and procedures of HIV should be made more accessible. ${ }^{16,17}$ These interventions include

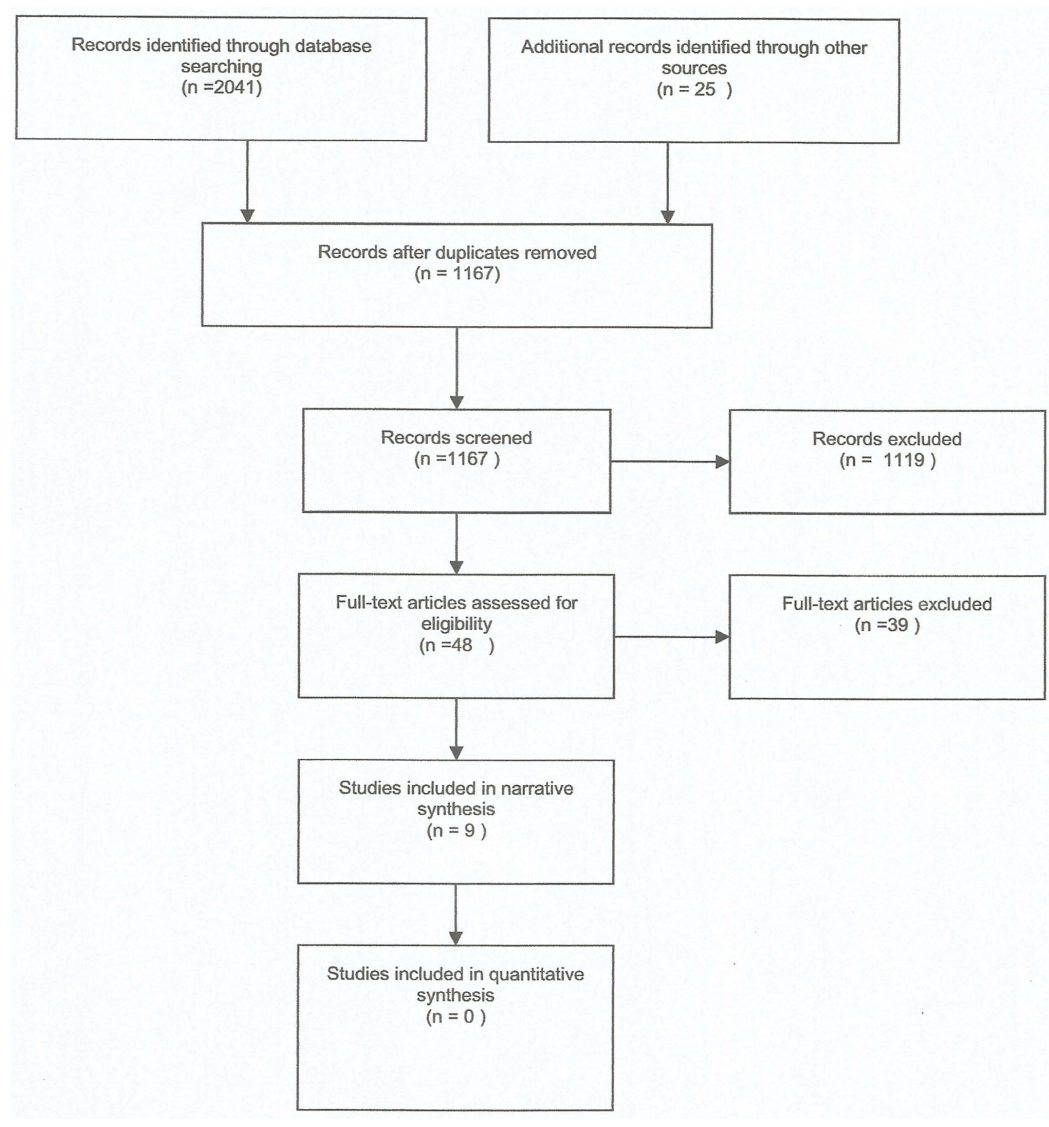

Figure I Flow diagram for the included studies. 
Table I Study domain characteristics of included studies

\begin{tabular}{|c|c|c|c|}
\hline Dormains & Interventions & $\begin{array}{l}\text { Number } \\
\text { of studies }\end{array}$ & Studies \\
\hline \multirow[t]{2}{*}{$\begin{array}{l}\text { Demand- } \\
\text { side }\end{array}$} & $\begin{array}{l}\text { I. Education campaigns delivered in } \\
\text { schools, health settings, communities, } \\
\text { media }\end{array}$ & Six & $\begin{array}{l}\text { Coates et al }(2008)^{10} \text {; Krishnaratne et al, }(2016)^{13} \text {; Amaugo et al }(2014)^{11} \text {; } \\
\text { Kirby et al }(2006)^{12} \text {; Paul-Ebhohimhen }(2008)^{14} \text { and Fonner et al }(2014)^{15}\end{array}$ \\
\hline & 2. Peer and social network-driven & Two & Coates et al $(2008)^{10}$ and Krishnaratne et al $(2016)^{13}$ \\
\hline Supply-side & $\begin{array}{l}\text { Mass-condom distribution, Needle- } \\
\text { syringe exchange programmes }\end{array}$ & Two & Blankenship et al $(2000)^{16}$ and Charania et al $(2011)^{17}$ \\
\hline
\end{tabular}

mass-condom distribution and needle-syringe exchange programs. The delivery platform for supply-side interventions is the health system.

One review by Pettifor et al evaluated interventions (cash) to improve HIV health outcomes. ${ }^{18}$ The authors of Pettifor et al review revealed reductions in sexual behavior and also a difference in HIV prevalence between young female receivers of cash transfers and the nonreceivers. Adherence interventions may seek to close the gap between behavioral intention and action by supporting ongoing adoption and use of preventive behaviors, including those that do and do not involve prevention products. According to the authors of Pettifor et al review, adherence interventions included those that target the social determinants of behavior, those based on incentives, peer-support and risk-reduction counseling to support ongoing prevention behaviors and skills. ${ }^{18}$ The delivery platform for adherence-side interventions is the community-based organization. $^{18}$

\section{Discussion}

This review is necessary because behavior change will need to remain a core component if the effectiveness of HIV prevention products, procedures and behavior is to increase in the future. ${ }^{19}$ HPC framework embodies three cascade theories: epidemiological, behavioral and social science with an integration of the supply side, demand side and the adherence side.

The supply-side aims to enhance the uptake and consistent use of HIV prevention in populations and subgroup populations; the demand side helps in the design while the adherence side helps in monitoring of program activities for HIV/AIDS. ${ }^{6}$ The evidence for the effectiveness of supply-side interventions is a well-timed reminder of the progress that can be made in HIV prevention through accessibility and availability of prevention products to populations in need of them. Consequently, it is believed that implementation of HPC in specific contexts and public health principles will deliver desired health outcomes.

From a previous review by Krishnaratne et al, the authors stated that interventions to increase supply of HIV prevention methods such as condoms or clean needles can be effective; however, the evidence arising from demand-side interventions to promote use of or adherence to prevention tools was uncertain, with some approaches likely to be effective and others showing no effect. ${ }^{13}$

Similarly, the findings of this mini-review show that HPC framework embodies three cascade theories: epidemiological, behavioral and social science with an integration of the supply side, demand side and the adherence side. As shown by the previous review by Blankenship et al and Charania et al, the supply side aims to enhance the uptake and consistent use of HIV prevention in populations and subgroup populations. ${ }^{16,17}$ Consequently, it is believed that implementation of HPC in specific contexts and public health principles will deliver desired health outcomes in Nigeria. However, this calls for concerted efforts. $^{9-21}$

The demand side involves the knowledge translation and the impact of its use on accessibility, acceptability, affordability of HPC products, services and procedures. These include condoms, voluntary male circumcision and anti-retro viral therapy amongst others. Furthermore, the background of cultural and gender appropriateness will influence the effective usage of HIV preventive services by the population. This is illustrated in the six studies included in this review, which all discussed the demandside interventions for HPC. ${ }^{10-15}$ These studies emphasized classic behavioral interventions such as information and education campaigns delivered in schools, health settings, communities and through the media. As shown in the included studies, the demand-side interventions involved peer and social network-driven interventions. Furthermore, the background of cultural and gender appropriateness will 
influence the effective usage of HIV preventive services by the population. In Nigeria, these interventions are likely to work because of the increasing use of social networking.

HPC theories have been in use and have long been promoted in international settings. These involve the promotion of efficacious prevention products; continuous and effective use of male condoms; oral microbicides; implementation of clean needles/syringes strategies; use of treatment as a type of prevention; pre-exposure prophylaxis (PrEP); voluntary male medical circumcision; conditional cash transfer; and other biomedical, behavioral and structural strategies. ${ }^{20-27}$ These interventions are applicable to Nigerian settings.

Nigeria is a large, multiethnic, multicultural, multiplex and diversely confounding society. ${ }^{27}$ HIV/AIDS in Nigeria is one of the HIV subepidemics in a generalized epidemic setting. ${ }^{28}$ Nigeria finds itself within interplay of spread of multiinteractive facilitating factors which include economic development and poverty. Thus, the adherence side of the domains was reviewed by Pettifor et al. ${ }^{18}$ The authors of Pettifor et al review evaluated interventions (cash) to improve HIV health outcomes and concluded that reductions in sexual behavior lead to a reduction in HIV prevalence and there was a difference in HIV prevalence between young female receivers of cash transfers and non-cash receivers. ${ }^{18}$ Adherence interventions will seek to close the gap between behavioral intention and action by supporting ongoing adoption and use of prevention behaviors, including those that do and do not involve prevention products. ${ }^{28,29}$ These are peculiar in developing countries, of which Nigeria is one. Although Highly Active Anti-Retroviral Therapy significantly reduced HIV/AIDS mortality, appropriate adherence level is recommended for viral suppression and therapeutic response in People Living with HIV/AIDS. ${ }^{19}$

Structural factors include the institutional practices that affect the health behavior of its people and help to increase the rate of new HIV infections abound in Nigeria. Among these are practices such as lack of autonomy in homes, families, communities and lack of inheritance rights. ${ }^{30}$ These gendered practices which mitigate against fundamental human rights and strengthen the feminization of poverty could be a major culprit for HIV spread. ${ }^{30}$ Most importantly, gender inequalities are a contextual need for different Nigerian communities. There should be continual improvement and adaptation to the changing Nigerian environment. ${ }^{31,32}$
The HPC approach has been applied in countries that have experienced successful outcomes in preventing new HIV infections. These countries include USA, Australia and Zimbabwe. ${ }^{4}$ For example, in the USA, HIV incidences decreased in men who have sex with men, while in Australia, there was a decrease in new incidents of HIV among intravenous drug users. ${ }^{4}$ However, the behavior above could not suffice for global South, rather the multilevel theories aligning socio-structural factors better helped to explain the increasing HIV prevalence in the global South. ${ }^{4}$

Examples of sociocultural factors that have contributed to the increasing prevalence of HIV in the global South include gender inequality, poverty, economic inequality, underdevelopment, globalization, economic migration and social stigmatization. ${ }^{5}$ Conditional cash transfers showed a reduction in the rate of HIV and herpes incidence, while in Uganda, there was success in a joint action program that cut across the three levels of HPC. ${ }^{4,26}$ In Thailand, using a 12-year span, multi-pronged program based on community-wide involvement, condom promotion and altered male social norms, there was a decrease in new HIV infections. Thus, structural interventions can aid possible declines in new HIV incidents and thereby sustain HIV prevention. ${ }^{3,26,32}$ The HPC is hoped to bring out the best practices of the biomedical, behavioral and structural activities from the three levels of intervention services. This will aid in identifying areas of gaps in the continuum of intervention activities in the cascade.

As HPC is an emerging new strategy, combining theories of epidemiological, behavioral and social sciences into program design and monitoring brings in a practicable paradigm shift from an emphasis in HIV treatment plan alone. ${ }^{5}$ The theories embody the needed technologies or risk reduction behaviors through which the program directly seeks to prevent new HIV infections. ${ }^{18,33-37}$

By contrast, Jones et al believe that the fight for the HIV pandemic should be country-specific, epidemiologically dependent on demographics and geographic peculiarities whilst focusing on high transmission groups with their different package of interventions. ${ }^{38}$ HIV prevention interventions must engage with people's everyday lives and be integrated into their social relations and social practices. $^{7}$ HIV combination implementation (HCI) is a strategy related to realistic, localized relevance of evidence-based approaches to support an increasing acceptance and quality of interventions for HIV prevention. ${ }^{34}$ In the field of HIV, HCI relates to the importance of 
emphasizing implementation especially in sub-Saharan nations that are plagued by socioeconomic issues. ${ }^{35}$ Nigeria has the second largest HIV disease burden globally of about 3.2 million persons with about 13 of its states driving the epidemic. ${ }^{35}$

A country-specific plan should be drawn up with the interactions of the perspectives of disparate stakeholders. This is in recognition of the widening impact of HIV/AIDS scourge in Nigeria on human development. It is important to have an understanding of the interaction of the disparate factors such as effect of economic policies that may reverse its people to poverty, migration, urbanization, gender inequalities with the accompanying stereotypical roles in a patriarchal context, lack of women's autonomy, violence against women, a widening effect of institutional challenges and political non-freedom. The developmental impact of HIV/AIDS influences the social systems on the micro and meso levels. Until poverty is reduced, the effective halt looked for in the HIV transmission dynamics and the capacity for improvement of the socioeconomic situation might not be easily attained. ${ }^{30}$ The developmental impact of HIV/ AIDS invariably affects human capabilities, widening economic and social navigation with untold negative effects especially on women's social safety nets. As such, we see an interweaving of a complex cyclical interrelation of cultural and political ideologies.

The first aspect is the demand side of the HPC that functions on the awareness of risk perceptions by potential users; their practices or influence on activities that can promote acceptance of HPC services, products and procedures. The total benefits are cognitively checked by any potential user before acceptance and possible usage. However, this incorporates the challenge of the extent of acceptance or use as it focuses at an individual level rather than population level which is the basis of public health prevention approach for diseases. Nevertheless, voluntary male medical circumcision has worked in Southern Africa where it has helped reduce HIV incidence. ${ }^{5}$ This is where community involvement of all stakeholders in HIV prevention, through knowledge translation activities like information, education and communication, will encourage and enhance participation for the uptake of HPC services.

The next is the supply side, which is evidence of the extent of good governance and leadership involvement toward the halting of the nation's HIV epidemic. The awareness of the determinants of HIV, especially the proximate and distal determinants of HIV, such as contextual sociocultural factors, should result in the delivery of the supply side of products. ${ }^{34}$ There should be multi-sectorial involvement of private and public participants at the programmatic level planning for the diverse strategic approaches by end users and also during program implementation and evaluation. The supply side should involve more health facility settings that are sited away from prying eyes of health workers. An example will be to offer privacy and ease of usage for adolescent users. This is an element of a human right approach to freedom of decision and choices. For instance, in the Scandinavian nations, there was the delivery of the clean needles and syringes away from the traditional health setting structure to the grassroot reach of the injecting drug users. However, in the USA, the federal policy is against the sponsorship of the usage of clean needles services and this can erode the positive achievements of HIV gains. ${ }^{19}$

The final aspect is at the adherence level. There should be an appreciation of the understanding of the benefits of the products involved in the HPC and the acceptability of the use of supplied HPC interventions. ${ }^{37,39}$ Hence, an effective monitoring and surveillance program is key to the understanding of the acceptance and acceptability of the whole model. The gains of HPC can be appreciated while any limitations seen with HPC are addressed through operational research. At the grassroot level, in the authors' experience, the use of behavioral strategies like the voluntary usage of adherence counseling drop in centers at health settings by these clients is a sign of acceptability for usage.

\section{Strengths and weaknesses}

The HPC aspects described above seem straightforward; however, there are different situations and scenarios that play out for a different population with the interplay of humans in a nonstatic environment. Variability in the dimensions of health and context specificity comes into cognizance. Therefore, appropriate prevention pattern for each locality should incorporate the complexities of human lives as this can overshoot and damage the prevention of new infections. The framework described so far shows the continuum of care for HIV. An understanding of the HPC is a desired goal for all concerned HIV stakeholders in order to achieve prevention of new HIV infections.

The stated scenario shows the interplay of the supply, demand and adherence sides: HIV care services to HIV prevention, which also involve socio-structural factors 
such as indirect cost, cultural sensitivity, positive masculinities that may affect gender challenges, reduction of attached stigma stemming from participation in in-school HIV prevention programs. Therefore, HPC is appreciated for a heterogeneity that incorporates diverse prevention needs. ${ }^{33}$ The use of a detailed and analytical path to constituting and appraising intervention program for HPC is needed. This may involve the promotion of continuous and consistent use of condoms, PrEP and annual test of HIV. ${ }^{38}$

There are obvious research gaps for continuing inquiry into HPC. There is a vital need for community-based participatory (CBPR) approaches at the three levels; demand, supply and adherence sides in Nigeria. However, the structures for CBPR, such as community capacity research building among others, need to be in place in Nigeria. CBPR, a collaborative community-driven research with academia, has been shown to be a successful public health intervention in global North due to health and social augmenting outcomes in affected groups.

\section{Conclusion}

Current published evidence on HPC in a Nigerian context is sparse. HPC allows for a paradigm shift and sequential process of events which will lead to the elimination of HIV. It provides an effective and progressive platform for the elimination of HIV, a shift from treatment to the successful prevention of HIV in a Nigerian setting. This calls for opportunities for researchers to enhance trial designs on HPC theory. The current paradigm by international bodies for a multi-approach management in HPC is a welcome idea. There is a need to adopt a harmonizing approach of the biomedical, behavioral and structural strategies that may eliminate new HIV infections.

\section{Abbreviations}

HPC, HIV prevention cascade; UNAIDS, United Nations Programme on HIV and AIDS; PrEP, pre-exposure prophylaxis; PIME, planning, implementation, monitoring, and evaluation, VMMC, voluntary male medical circumcision; CCGHR, Canadian coalition for global health research; CBPR, community-based participatory research; HCI, HIV combination implementation.

\section{Data sharing statement}

All data generated or analyzed during this study are contained within the manuscript.

\section{Author contributions}

All authors contributed to data analysis, drafting or revising the article, gave final approval of the version to be published, and agree to be accountable for all aspects of the work.

\section{Disclosure}

The authors report no conflicts of interest in this work.

\section{References}

1. NACA. National Strategic Framework on HIV and AIDS: 2017; 2017-2021. Available from: https://naca.gov.ng/national-guidelineshiv-prevention-treatment-care-2/. Accessed January 3, 2019.

2. NACA. Nigeria GARPR 2015, 2015. Available from: https://naca.gov ng/nigeria_garpr_2015_report/. Accessed January 3, 2019

3. Bain LE, Nkoke C, Noubiap JJN. UNAIDS 90- 90-90 targets to end the AIDS epidemic by 2020 are not realistic: comment on "Can the UNAIDS 90- 90-90 target be achieved? A systematic analysis of national HIV treatment cascades". BMJ Glob Health. 2017;2(2): e000227. doi:10.1136/bmjgh-2016-000227

4. Poundstone KE, Strathdee SA, Celentano DD. The social epidemiology of human immunodeficiency virus/acquired immunodeficiency syndrome. Epidemiol Rev. 2004;26(1):22-35. doi:10.1093/epirev/mxh005

5. UNAIDS. Combination HIV Prevention: Tailoring and coordinating Biomedical, behavioural and Structural Strategies to reduce New HIV infections. 2010. A UNAIDS discussion Paper. Available from: www. unaids.org.

6. Hargreaves JR, Delany-Moretlwe S, Hallett TB, et al. The HIV prevention cascade: integrating theories of epidemiological, behavioural, and social science into programme design and monitoring. Lancet HIV. 2016;3(7):e318-22. doi:10.1016/S2352-3018(16)30063-7

7. Isbell MT, Kilonzo N, Mugurungi O, Bekker LG. We neglect primary HIV prevention at our peril. Lancet HIV. 2016;3(7):e284-e285. doi:10.1016/S2352-3018(16)30058-3

8. Kippax S, Stephenson N. Beyond the distinction between biomedical and social dimensions of HIV prevention through the lens of a social public health. Am J Public Health. 2012;102(5):789-799. doi:10.2105/AJPH.2011.300594

9. Waaler HT, Piot MA. The use of an epidemiological model for estimating the effectiveness of tuberculosis control measures: sensitivity of the effectiveness of tuberculosis control measures to the coverage of the population. Bull World Health Organ. 1969;41(1):75.

10. Coates TJ, Richter L, Caceres C. Behavioural strategies to reduce HIV transmission: how to make them work better. Lancet. 2008;372:669-684.

11. Amaugo LG, Papadopoulos C, Ochieng BM, Ali N. The effectiveness of HIV/AIDS school-based sexual health education programmes in Nigeria: a systematic review. Health Educ Res. 2014;29:633-648. doi:10.1093/her/cyu002

12. Kirby D, Obasi A, Laris BA. The effectiveness of sex education and HIV education interventions in schools in developing countries. World Health Organ Tech Rep Ser. 2006;938:103-150.

13. Krishnaratne S, Hensen B, Cordes J, Enstone J, Hargreaves JR. Interventions to strengthen the HIV prevention cascade: a systematic review of reviews. Lancet HIV. 2016;3:e307-17. doi:10.1016/S23523018(16)30038-8

14. Paul-Ebhohimhen VA, Poobalan A, van Teijlingen ER. A systematic review of school-based sexual health interventions to prevent STI/HIV in sub-Saharan Africa. BMC Public Health. 2008;8:4. doi:10.1186/ 1471-2458-8-4

15. Fonner VA, Armstrong KS, Kennedy CE, O'Reilly KR, Sweat MD. School based sex education and HIV prevention in low- and middleincome countries: a systematic review and meta-analysis. PLoS One. 2014;9:e89692. doi:10.1371/journal.pone.0089692 
16. Blankenship KM, Bray SJ, Merson MH. Structural interventions in public health. AIDS. 2000;14:S11-21. doi:10.1097/00002030200006001-00003

17. Charania MR, Crepaz N, Guenther-Gray C, et al. Efficacy of structural-level condom distribution interventions: a meta-analysis of U.S. and international studies, 1998-2007. AIDS Behav. 2011;15:12831297. doi:10.1007/s10461-010-9812-y

18. Pettifor A, MacPhail C, Nguyen N, Rosenberg M. Can money prevent the spread of HIV? A review of cash payments for HIV prevention. AIDS Behav. 2012;16(7):1729-1738. doi:10.1007/ s10461-012-0240-z

19. UNAIDS.The gap report. Geneva, Switzerland. 2014 May 4. Available from: http://www.unaids.org/en/media/unaida/contentas sests/documents/unaidspublication/2014/UNAIDS_gap_report_en_ pdf.

20. Dehne KL, Dallabetta G, Wilson D, et al. HIV Prevention 2020: a framework for delivery and a call for action. Lancet HIV. 2016;3(7): e323-32. doi:10.1016/S2352-3018(16)30035-2

21. Wilton J, Broeckaert L. Enhancing HIV Prevention: the Need to Better Link and Integrate Services for Individuals at Highest Risk of HIV Infection. Prevention in focus spotlight on programming and research, Canada: 2016

22. Vernick JS, Burris S, Strathdee SA. Public opinion about syringe exchange programmes in the USA: an analysis of national surveys. Int J Drug Policy. 2003;14(5-6):431-435. doi:10.1016/S0955-3959 (03)00144-0

23. Jiang J, Yang X, Ye L, et al. Pre-exposure prophylaxis for the prevention of HIV infection in high risk populations: a meta-analysis of randomized controlled trials. PLoS One. 2014;9(2):e87674. doi:10.1371/journal.pone.0087674

24. Szabo R, Short RV. How does male circumcision protect against HIV infection? BMJ. 2000;320(7249):1592. doi:10.1136/bmj.320.7249. 1592

25. Baird SJ, Garfein RS, McIntosh CT, Özler B. Effect of a cash transfer programme for schooling on prevalence of HIV and herpes simplex type 2 in Malawi: a cluster randomised trial. Lancet. 2012;379 (9823):1320-1329. doi:10.1016/S0140-6736(11)61709-1

26. Kumar N. Democratic developmental state in India. Indian J Public Admin. 2016;62(2):226-248. doi:10.1177/0019556120160202

27. Tanser F, de Oliveira $T$, Maheu-Giroux M, Bärnighausen $T$. Concentrated HIV sub-epidemics in generalized epidemic settings. Curr Opin HIV AIDS. 2014;9(2):115. doi:10.1097/COH.000000 0000000034
28. Parkhurst JO. Structural approaches for prevention of sexually transmitted HIV in general populations: definitions and an operational approach. $J$ Int AIDS Soc. 2014;17(1):19052. doi:10.7448/ IAS.17.1.19052

29. Anwuluorah OP. The prevalence of HIV/AIDS Epidemic in Anambra State, Nigeria: Exploring Gender, Cultural and Socio-Religious Perspectives. Afrrev Ijah. 2017;6(1):39-53.

30. Green EC, Halperin DT, Nantulya V, Hogle JA. Uganda's HIV prevention success: the role of sexual behavior change and the national response. AIDS Behav. 2006;10(4):335-346. doi:10.1007/ s10461-006-9073-y

31. Sumartojo E. Structural factors in HIV prevention: concepts, examples, and implications for research. Aids. 2000;14:S3-S10. doi:10.1097/00002030-200006001-00002

32. Horn T, Sherwood J, Remien RH, Nash D, Auerbach JD. Treatment Action Group and Foundation for Aids Research HIV Prevention Continuum Working Group. Towards an integrated primary and secondary HIV prevention continuum for the United States: a cyclical process model. J Int AIDS Soc. 2016;19(1):21263.

33. Chang LW, Serwadda D, Quinn TC, Wawer MJ, Gray RH, Reynolds SJ. Combination implementation for HIV prevention: moving from clinical trial evidence to population-level effects. Lancet Infect Dis. 2013;13(1):65-76. doi:10.1016/S1473-3099(12)70273-6

34. Demographic N. Health Survey. Abuja, Nigeria, and Rockville, Maryland, USA: NPC and ICF International. 2013. National Population Commission (NPC)[Nigeria] and ICF International. 2014 Jun: 127-154.

35. Cohen D Poverty and HIV/AIDS in sub-Saharan Africa. Available from www.popline.org. Assessed March 2nd, 2018.

36. Blankenship KM, Friedman SR, Dworkin S, Mantell JE. Structural interventions: concepts, challenges and opportunities for research. $J$ Urban Health. 2006;83(1):59-72. doi:10.1007/s11524-005-9007-4

37. Johnson WD, Diaz RM, Flanders WD, et al. Behavioral interventions to reduce risk for sexual transmission of HIV among men who have sex with men. Cochrane Database Syst Rev. 2008;(3). doi:10.1002/ 14651858.CD001230.pub2.

38. Jones A, Cremin I, Abdullah F, et al. Transformation of HIV from pandemic to low-endemic levels: a public health approach to combination prevention. Lancet. 2014;384(9939):272-279. doi:10.1016/ S0140-6736(13)62230-8

39. Volmink J, Dare L. Addressing inequalities in research capacity in Africa. BMJ. 2005; 331(7519):705-706.
HIV/AIDS - Research and Palliative Care

\section{Publish your work in this journal}

HIV/AIDS - Research and Palliative Care is an international, peerreviewed open-access journal focusing on advances in research in HIV, its clinical progression and management options including antiviral treatment, palliative care and public healthcare policies to control viral spread. The manuscript management system is completely online and includes a very quick and fair peer-review system, which is all easy to use. Visit http://www.dovepress.com/testimonials.php to read real quotes from published authors. 